\title{
Derecho Corporativo
}

José Antonio Gaspar

Profesor de Derecho Comercial y Derecho Civil

Universidad Diego Portales

\section{Derecho Corporativo}

Deber de diligencia y CUIDAdo DE LOS DIRECTORES DE SOCIEDADES anónimas. Caso La Polar. SuperinTENDENCIA DE VALORES Y Seguros, RESOLUCIONES EXENTAS $\mathrm{N}^{\circ} 073,074$, 075, 076, 077, 078, 079, 080, 081 Y 082, TODAS DE 9 DE MARzo de $2012^{1}$

Nadie podrá dudar que el caso La Polar ha resultado ser el principal escándalo corporativo experimentado en nuestro país, llegando a ser conocido como el "Enron Chileno"2. Además de su importancia, uno puede destacar las múltiples aristas desde las cuales puede abordarse: Derecho del Consumidor en cuanto a la situación de las repactaciones unilaterales que

${ }^{1}$ El comentarista de esta jurisprudencia administrativa agradece el apoyo de los alumnos de la Facultad de Derecho de la Universidad Diego Portales, Muriel Hernández, Damián Mura, Sergio Troncoso y Carlos Toloza, en el análisis de la documentación que se comenta.

${ }^{2}$ Véase el artículo de prensa "La Polar y su parecido con otros escándalos financieros", en Economía y Negocios, El Mercurio, Santiago, 3 de julio de 2011. afectaron a los tenedores de tarjetas de esta casa comercial ${ }^{3}$, Derecho del Mercado de Valores, en cuanto a los casos de infracción a la normativa de información privilegiada y a las eventuales infracciones incurridas por los auditores externos y clasificadores de riesgo que no se percataron del fraude existente y certificaron la información financiera o se pronunciaron sobre la base de ella ${ }^{4}, y$ Derecho Corporativo, en cuanto a la responsabilidad de los directores por

${ }^{3}$ Véanse los comentarios formulados por Francisca BARrientos, "Los derechos de los consumidores en el caso La Polar"; Hernán Corral Talciani, Caso La Polar: repactaciones irregulares y reparación a los consumidores y José RoA RAMírez, "La Polar y modificaciones unilaterales de los contratos", en Gaceta Jurídica, edición especial Análisis doctrinario y jurisprudencial del caso La Polar, Santiago, Legal Publishing Chile, 2011.

${ }^{4}$ Véase nuestra ponencia José Antonio Gaspar, "Responsabilidad civil de los gatekeepers en el mercado de capitales: análisis de la responsabilidad civil de los auditores externos, clasificadoras de riesgo y analistas financieros en el Caso La Polar", en Fabián Elorriaga de Bonis (coord), Estudios de Derecho Civil VII,Jornadas Nacionales de Derecho Civil, Viña del Mar, 2011, Santiago, Legal Publishing Chile, 2012. 
no haberse percatado de la situación que ocurría en la compañía.

Al respecto, nos interesa centrarnos precisamente en el deber de diligencia y cuidado que debieron haber empleado los directores de esta empresa y que fue analizado por la Superintendencia de Valores y Seguros.

1. Mediante las resoluciones exentas $\mathrm{N}^{\circ} 073,074,075,076,077,078,079$, 080, 081 y 082, todas de 9 de marzo de 2012, la SVS estimó haber constatado los siguientes hechos:

En La Polar se desarrolló una práctica que tenía por objetivo poner al día a clientes que se encontraban en mora, la cual se materializaba mediante la renegociación sin su consentimiento, o unilateral, de los créditos otorgados a ellos. Quienes a la fecha de la renegociación se encontraban en mora, luego de ella eran considerados como clientes al día para todos los efectos.

Esta práctica de renegociaciones unilaterales (denominada "normalización”) se inició en el año 2001 de forma muy acotada, aumentando su utilización a contar del año 2002. Inicialmente, la normalización era aplicada a clientes con moras de más de ciento ochenta días. Luego, el procedimiento se incrementó, considerando clientes que se encontraban en tramos de moras menores. Así, la práctica de normalización se convirtió en un procedimiento rutinario e institucionalizado en el área de cobranzas de La Polar.

La normalización era efectuada por personas del call center de La Po-

lar, provocando aumento de gastos por comisiones para estos operarios, que cumplían sistemáticamente las metas impuestas, un uso indiscriminado de esta práctica por los operarios y la distracción de los operarios de las labores de cobranza para dedicarse a efectuar las renegociaciones. Para eliminar estos efectos indeseados en el área de call center, en mayo de 2009, la gerencia corporativa de productos financieros requirió a la gerencia de informática el desarrollo de una herramienta computacional que "normalizara" clientes mediante procesos batch, esto es, procesos por bloques de datos. Luego, los procesos de renegociaciones automáticas eran determinados por la gerencia corporativa de productos financieros, impartiendo instrucciones al área de informática.

$\mathrm{El}$ aumento del número de clientes renegociados unilateralmente empezó a impactar la situación financiera de la cartera de La Polar: la tasa de pago de la cartera de créditos ascendía a 4,4\%, cuando debía ser del orden del 7\% al 7,5\%. Además, se necesitaba normalizar a quienes se encontraban en mora, porque se detectó que un número significativo de renegociados y repactados tendían a mantenerse en dicha condición, creando el problema de recaudación de la cartera de La Polar. Por ello, el año 2008 se formó un comité integrado exclusivamente por personal de la gerencia corporativa de productos financieros. Se identificó el universo de clientes sujetos a la normalización con una clasificación sobre la base 
de colores según el período en que no presentaban pagos. Con las múltiples renegociaciones unilaterales, el monto de la cartera de colores aumentaba, aun cuando el número de clientes disminuía. La cartera de colores fue objeto de seguimiento, implementándose campañas para cobrar sin gran recaudación.

En el año 2010, en la gerencia corporativa se formó un comité de cobranza para desarrollar mejores estrategias de cobranza de los sujetos normalizados con mayor probabilidad de cobro. Este comité estaba al tanto de la práctica de normalizar, que denominaba revolving, y a quienes se incluía en la cartera de colores los denominaba "energizados".

Por su parte, el efecto de las renegociaciones unilaterales en el negocio crediticio de La Polar y en su situación financiera era evidenciado en el contenido de los informes preparados por la gerencia de gestión. Los reportes incluían información relacionada con la marcha de los distintos negocios desarrollados por La Polar, con informes respecto de su negocio financiero y su cartera crediticia, incluyendo información sobre las renegociaciones. Para la preparación de estos informes, la gerencia de gestión mantenía permanente contacto con la gerencia corporativa de productos financieros.

Además de la información contenida en los reportes preparados por la gerencia de gestión, al interior de La Polar se elaboraron otros informes reportando la existencia de un volumen elevado de renego- ciaciones, como lo hizo la gerencia de contraloría. Ésta nunca efectuó presentaciones al directorio ni al comité de directores, ni fue requerida para ello.

En el año 2009, por las masivas renegociaciones unilaterales, aumentó el número de reclamos de consumidores, que motivaron comunicaciones entre La Polar y el SERNAC. Así, en el año 2010 se gatilló un proceso de mediación colectiva ante el SERNAC, en que La Polar comprometió la adopción de medidas destinadas a resolver los problemas denunciados por los clientes.

El directorio y el comité de directores de La Polar eran informados acerca del desempeño de la cartera crediticia a través de presentaciones periódicas efectuadas por la gerencia de la compañía. Hasta mayo de 2010, las presentaciones eran efectuadas sin una frecuencia definida; luego dejaron de efectuarse porque dicha información se incluía en los reportes mensuales que eran presentados al directorio. La SVS detalla sesiones en que se informó al directorio sobre la clasificación de clientes, el plan de recuperación de los créditos energizados e, incluso, la existencia de consumidores con más de una renegociación. El directorio y el comité de directores se habrían limitado a requerir que se analizara el impacto en las provisiones de la compañía. Sólo en las sesiones de junio de 2011, con motivo de una demanda del SERNAC, tanto el comité de directores como el directorio tomó 
conocimiento de las renegociaciones unilaterales y el real efecto en el nivel de provisiones, incluyendo las provisiones adicionales requeridas para regularizar la situación.

Así, mediante hecho esencial de fecha 9 de junio de 2011, el directorio informó al mercado que el impacto de esas prácticas significaba una provisión adicional de ciento cincuenta a doscientos mil millones de pesos, cifra que aumentó a MM\$420.072 a través del hecho esencial de $17 \mathrm{de}$ junio de 2011. Dicho volumen de provisionales adicionales significó que La Polar registrara un patrimonio negativo de $\mathrm{MM} \$ 116.022$ en sus estados financieros al 31 de julio de 2011.

2. Sobre la base de los hechos antes referidos, la SVS dio inicio a un procedimiento de investigación destinado a determinar las eventuales infracciones a la normativa aplicable a las sociedades anónimas por parte de los directores de La Polar, señores: Heriberto Urzúa Sánchez, Baltazar Sánchez Guzmán, Andrés Ibáñez Tardel, Manuel Francisco Gana Eguiguren, Fernando Franke García, Norberto Morita, Raúl Sotomayor Valenzuela, Jacques Louis de Montalembert, René Cortázar Sánz y María Gracia Cariola Cubillos. En dicho contexto, la SVS formuló cargos contra estos directores, mediante los oficios reservados $\mathrm{N}^{\text {os }} 331,332$, 333, 334, 335, 336, 337, 338, $339 \mathrm{y}$ 340 , respectivamente, todos de 13 de julio de 2011, imputándoles:

- falta de diligencia al no observar una conducta orientada a mejorar los controles internos de La Polar, por cuanto no establecieron mecanismos de control destinados a prevenir los eventuales problemas derivados de la presencia de conflictos de interés que enfrentaban los ejecutivos principales de La Polar en su calidad de beneficiarios de planes de incentivos asociados a los resultados de la compañía, y no requerir a la administración la contratación de un gerente de contraloría interna y un fortalecimiento de la independencia de dicha área respecto de la gerencia de la compañía.

- incumplimiento del artículo 39 de la Ley de Sociedades Anónimas, al no haber ejercido de forma adecuada y conforme a derecho las facultades pertinentes respecto del conocimiento de la situación financiera de La Polar en relación con las provisiones de la cartera de crédito. La SVS formuló este reproche, por una parte porque aun cuando existía información relevante sobre ello, los directores se limitaron a solicitar información respecto del deterioro de la cartera, sin satisfacer el deber de cuidado que implica necesariamente informarse del resultado de las consultas realizadas a la administración y de la marcha de la empresa $y$, por otra parte, por resultar 
insuficiente la frecuencia y profundidad con que el $\mathrm{Di}$ rectorio recibía información sobre el área financiera de La Polar.

- incumplimiento del estándar de conducta establecido en el artículo 41 de la Ley de Sociedades Anónimas, atendido el tiempo que ocuparon en el cargo de directores de La Polar y su participación en las respectivas sesiones de directorio.

Además, en el caso de los señores: Andrés Ibáñez, Fernando Franke, Raúl Sotomayor, Jacques de Montalembert, René Cortázar y Manuel Gana, la SVS sostuvo el incumplimiento de los especiales deberes de cuidado que se le imponían por integrar el comité de directores de una sociedad anónima, infringiendo lo dispuesto en el artículo 50 bis de la Ley de Sociedades Anónimas.

Todos estos directores dieron respuesta a los cargos de la SVS, formulando una serie de descargos.

3. En relación con el reproche relativo al inadecuado diseño de los mecanismos de control interno vigentes en La Polar, en los descargos de los directores se sostuvo que, al menos en las sociedades anónimas que integran el IPSA, queda de manifiesto que en muchas de ellas, el área de auditoría interna o contraloría aparece como subordinada, directa o indirectamente, a la gerencia general, como ocurría en La Polar, lo que jamás había sido observado ni menos objetado por la SVS ni por la SBIF, en su caso. Lo anterior, haría razonable pensar que tal estructura no tenía nada de reprochable, en especial porque podría ser un factor de confianza legítima de los directores en el actuar de la SVS.

$\mathrm{Al}$ respecto, en sus resoluciones exentas, la SVS planteó que la actuación de los directores debía ser evaluada considerando que, dentro de los aspectos inherentes a las funciones que desempeña el directorio en la administración superior de una compañía, se encuentra efectuar la supervisión y monitoreo permanente de la correcta ejecución de las políticas fijadas por dicho órgano a través de las respectivas agencias. Ello supone el establecimiento de mecanismos y procedimientos que permitan que la información relevante de la compañía fluya hacia la dirección superior, y sea en concreto recibida y procesada por el directorio, como también, controlar las condiciones para que dichos procedimientos funcionen correcta y eficientemente.

Debemos destacar que, en el caso La Polar, la SVS no cuestionó una determina estructura de organización, sino que no existiese una preocupación ni interés alguno de parte de los directores por el desarrollo de las funciones de auditoría interna, al punto que la creación de la unidad de contraloría interna se produjo para el cumplimiento de una circular de la SBIF, y no por iniciativa o por el impulso del directorio. Además, el directorio no requirió en ningún momento informes preparados por dicha área, de forma de haber constatado si ésta había efec- 
tuado revisiones al respecto, como el resultado de las mismas. Todo lo anterior, denotaría un total y completo abandono por los directores de las labores de control que corresponden a un director en el contexto de la superior administración de la compañía, con el objetivo de verificar el cumplimiento de las políticas y lineamientos establecidos por el directorio, lo que en gran medida, a juicio de la SVS, facilitó el aumento de las renegociaciones unilaterales en el tiempo, y significó que el crecimiento del negocio financiero se verificara al margen de las políticas de la compañía.

4. En relación con el reproche relativo a un incumplimiento de su deber de supervigilancia, se sostuvo en los descargos de los directores que, de acuerdo a los "Principios de Gobierno Corporativo de la OCDE", los directores tienen el derecho a depositar una legítima confianza en los ejecutivos de la compañía, sin que pueda formulárseles un reproche si no existen razones fundadas y justificadas para dudar de su comportamiento. Además, los directores se encontraban en una situación en que los ejecutivos principales de la compañía ocultaban información, lo cual les impidió tomar conocimiento real de la situación financiera, sin que los directores tuviesen la obligación de investigar antecedentes o información que la administración no revele. Finalmente, los directores sostuvieron que tenían una legítima expectativa y confianza en la revisión efectuada por el auditor de

los estados financieros de La Polar, dadas sus credenciales, expertise y alcance de los servicios ofrecidos, como, asimismo, en las opiniones de entidades especializadas como las clasificadoras de riesgo, cuyos informes en ningún momento revelaron riesgos de no pago de deudas ni objetaron el nivel de provisiones de la compañía.

$\mathrm{Al}$ respecto, en sus resoluciones exentas, la SVS sostuvo que la confianza legítima que los directores deben depositar en el actuar de la administración de la compañía no puede significar en modo alguno relevar a los directores de los deberes de cuidado a que están legalmente obligados, como de ejecutar y disponer las medidas de control y resguardo que sean necesarias para cautelar los intereses de la compañía y sus accionistas. Lo anterior, más aún, cuando, a juicio de la SVS, en este caso existían antecedentes suficientes como para que los directores desconfiaran no sólo de la fiabilidad de la información que recibían de la administración sino del actuar mismo de esta última.

En el caso concreto, la SVS sostuvo que los directores debieron haber ejercido el derecho consagrado en el artículo 39, que descansa sobre la premisa de que debe ser ejercido por quien tiene deberes fiduciarios respecto de la compañía y sus accionistas, por lo que no se ejecuta ni realiza a favor de quien lo detenta, sino a favor y en beneficio de los intereses de los terceros respecto de los cuales existe tal deber. Dado que 
éste cede a favor de los accionistas de la compañía, ha de ser ejercido por el director en cuanto ello sea necesario y le permita realizar su labor de tal, cuestión que fue omitida en este caso.

La SVS agregó que de dichos deberes de cuidado tampoco quedan eximidos los directores por el hecho de que los diversos informes emitidos por la empresa auditora externa y las clasificadoras de riesgo no manifestaran reparo alguno a la situación financiera de la compañía. Ello, más aún, dado que la SVS consideró que los directores estaban en condiciones de obtener información interna a través del derecho consagrado en el artículo 39 de la Ley de Sociedades Anónimas y por las instancias de auditoría interna que la propia compañía contemplaba, y que fueron ignoradas.

5. En relación con el reproche relativo al estándar de conducta establecido en el artículo 41 de la Ley de Sociedades Anónimas, en los descargos de los directores se sostuvo que la SVS, por la vía administrativa de la formulación de cargos, elevaba el nivel de diligencia impuesto por esta norma, correspondiente a la culpa leve, al nivel máximo de cuidado, haciendo responsables a los directores de la culpa levísima, lo cual sólo resultaría procedente a través de una modificación legal. Asimismo, se sostuvo la aplicación en Chile de los principios que en materia de gobierno corporativo contempla la OCDE, en especial la regla denominada Business Judgment Rule o Regla del Juicio de Negocio. Conforme a ella, la obligación que asumen los directores al aceptar el cargo no es la de asegurar el éxito económico de la empresa o evitar un fraude, dado que ello los convertiría en responsables de los acontecimientos perjudiciales que exceden de la diligencia exigible. La obligación de los directores sería la de desempeñar sus funciones cumpliendo los deberes impuestos por las leyes y los estatutos en procura de satisfacer el interés social. Así, el juicio de diligencia de los directores debe realizarse sobre la oportunidad o razonabilidad de su adopción o falta de adopción en el momento determinado, y ello aun cuando el resultado haya sido desastroso. Se sostuvo que para la SVS resultaba obligatorio el cumplimiento de este principio, por lo que sólo podría sancionar a directores en casos de negligencia grave o grosera, correspondiéndole a la SVS la carga de la prueba y no pudiendo sostenerse el actuar negligente de los directores en el resultado del negocio.

$\mathrm{Al}$ respecto, en sus resoluciones exentas, la SVS sostuvo que los deberes de cuidado propios de los directores de sociedades anónimas establecidos según el patrón de conducta del artículo 41 de la Ley de Sociedades Anónimas, deben adoptarse en consideración, entre otros parámetros, al interés comprometido en una sociedad anónima de las características de La Polar. En ella no sólo estaba comprometido el interés particular de la misma sociedad y sus accionistas sino, también, el interés público derivado de su con- 
dición de sociedad anónima abierta, emisora de valores, que recurre al financiamiento público, sujeta a un régimen especial de fiscalización por la autoridad que descansa en bienes jurídicos como la fe pública y la transparencia, competencia y equidad en el mercado. Por todo ello, la SVS sostuvo que el ejercicio de los deberes y derechos que entraña el cargo de director debe estar a la altura de la magnitud e importancia del interés que debe cautelarse.

Por todo ello, la SVS concluyó que el reproche efectuado de incumplimiento del referido deber de cuidado, lejos de importar una alteración al nivel de culpa del cual responde los directores, simplemente corresponde al análisis de las medidas que un director medio de una sociedad anónima, de las características de La Polar, debía adoptar. Lo anterior, más an cuando, a juicio de la SVS, resultaban evidentes y numerosos los indicios y señales que alertaban de la situación financiera de la compañía, los que fueron ignorados y no procesados por los directores.

6 . Finalmente, los directores que permanecieron menos de un año en el Directorio hicieron presente en sus descargos que no les correspondía ser evaluados con el mismo criterio con el que debían ser evaluados directores históricos de La Polar, quienes poseían mayor conocimiento y experiencia en los asuntos de la entidad.

Sobre el particular, en sus resoluciones exentas, la SVS señaló que, si bien la permanencia de un director en el ejercicio de su cargo, y particu-

larmente el período de adaptación al mismo, era un factor que podía ser considerado para efectos de evaluar la responsabilidad de estos directores, en este caso no podía importar la exoneración de su responsabilidad ante incumplimientos al estándar de cuidado exigido por la ley.

7. Sobre la base de éstas y otras consideraciones, el 9 de marzo de 2012, la SVS sancionó:

- mediante resolución exenta Nº73, a Andrés Ibáñez Tardel, quien fue director y miembro del comité de directores de La Polar entre mayo de 2004 y mayo de 2011, con multa, a beneficio fiscal, ascendente a UF 3.500, por infracción al artículo 41 en relación con los artículos 39 y 50 bis de la Ley de Sociedades Anónimas, sobre deberes de cuidado y diligencia de los directores e integrantes del comité de directores 5 .

- mediante resolución exenta $\mathrm{N}^{\circ} 074$, a Fernando Franke García, quien fue director de La Polar entre abril de 2004 y abril de 2011 y miembro

${ }^{5}$ Contra la resolución exenta $\mathrm{N}^{\circ} 073$, el señor Ibáñez interpuso recurso de reposición ante la misma SVS, el cual fue rechazado en todas sus partes mediante resolución exenta $\mathrm{N}^{\circ} 134$ de 23 de marzo de 2012. Por ello, el señor Ibáñez dedujo acción de reclamación en juicio sumario contra estas resoluciones que, a la fecha de este comentario, está aún tramitándose en primera instancia ante el $30^{\circ}$ Juzgado Civil de Santiago bajo el tol C-6650-2012. 
del comité de directores de La Polar entre mayo de 2004 y mayo de 2011, con multa, a beneficio fiscal, ascendente a UF 3.500, por la misma infracción ${ }^{6}$.

- mediante resolución exenta $\mathrm{N}^{\circ} 075$, a Baltazar Sánchez Guzmán, quien fue director de La Polar entre agosto de 2003 y abril de 2011, con multa, a beneficio fiscal, ascendente a UF 2.800, por infracción al artículo 41 en relación con el artículo 39 de la Ley de Sociedades Anónimas, sobre deberes de cuidado y diligencia de los directores ${ }^{7}$.

- mediante resolución exenta №76, a Heriberto Urzúa Sánchez, quien fue drector de La Polar entre abril de 2007 y abril de 2011, con multa, a beneficio fiscal, ascendente a UF 2.800, por la misma infracción ${ }^{8}$.

${ }^{6}$ Contra la resolución exenta $\mathrm{N}^{\circ} 074$, el señor Franke dedujo acción de reclamación en juicio sumario que, a la fecha de esta comentario, está aún tramitándose en primera instancia ante el $18^{\circ} \mathrm{Juzgado}$ Civil de Santiago bajo el rol C-6291-2012.

${ }^{7}$ Contra la resolución exenta $\mathrm{N}^{\circ} 075$, el señor Sánchez dedujo acción de reclamación en juicio sumario que, a la fecha de esta comentario, está aún tramitándose en primera instancia ante el $17^{\circ}$ Juzgado Civil de Santiago bajo el rol C-6554-2012.

${ }^{8}$ Contra la resolución exenta $\mathrm{N}^{\circ} 076, \mathrm{el}$ señor Urzúa dedujo acción de reclamación en juicio sumario que, a la fecha de esta comentario, está aún tramitándose en primera instancia ante el $30^{\circ}$ Juzgado Civil de Santiago bajo el Rol C-6531-2012.
- mediante resolución exenta N077, a Raúl Sotomayor Valenzuela, quien fue director y miembro del comité de directores de La Polar entre mayo de 2004 y junio de 2009, con multa, a beneficio fiscal, ascendente a UF 2.000, por infracción al artículo 41 en relación a los artículo 39 y 50 bis de la Ley de Sociedades Anónimas, sobre deberes de cuidado y diligencia de los directores e integrantes del comité de directores ${ }^{9}$.

- mediante Resolución Exenta $\mathrm{N}^{\circ} 078$, a Norberto Morita, quien fue director de La Polar entre agosto de 2003 y junio de 2009, con multa, a beneficio fiscal, ascendente a UF 1.500 , por infracción al artículo 41 en relación a los artículo 39 de la Ley de Sociedades Anónimas, sobre deberes de cuidado y diligencia de los directores. ${ }^{10}$

- mediante resolución exenta $\mathrm{N}^{\circ} 079$, a Jacques Louis de Montalembert, quien fue director de La Polar entre noviembre de

${ }^{9}$ Contra la resolución exenta $\mathrm{N}^{\circ} 077$, el señor Sotomayor dedujo acción de reclamación en juicio sumario que, a la fecha de esta comentario, está aún tramitándose en primera instancia ante el $22^{\circ} \mathrm{Juzgado}$ Civil de Santiago bajo el rol C-6676-2012.

${ }^{10}$ Contra la resolución exenta $\mathrm{N}^{\circ} 078$, el señor Morita dedujo acción de reclamación en juicio sumario que, a la fecha de este comentario, está aún tramitándose en primera instancia ante el $10^{\circ} \mathrm{Juzgado}$ Civil de Santiago bajo el Rol C-6696-2012. 
2006 y diciembre de 2009 y miembro del comité de directores de La Polar entre junio de 2009 y enero de 2010 , con multa, a beneficio fiscal, ascendente a UF 1.800, por infracción al artículo 41 en relación con los artículos 39 y 50 bis de la Ley de Sociedades Anónimas, sobre deberes de cuidado y diligencia de los directores e integrantes del comité de directores ${ }^{11}$.

- mediante resolución exenta Nº80, a María Gracia Cariola Cubillos, quien fue directora de La Polar entre noviembre de 2010 y abril de 2011, con multa, a beneficio fiscal, ascendente a UF 400, por infracción al artículo 41 en relación con el artículo 39 de la Ley de Sociedades Anónimas, sobre deberes de cuidado y diligencia de los directores ${ }^{12}$.

- mediante resolución exenta №81, a René Cortázar Sánz,

${ }^{11}$ Contra la resolución exenta $\mathrm{N}^{\circ} 079$, el señor De Montalembert dedujo acción de reclamación en juicio sumario que, a la fecha de este comentario, está aún tramitándose en primera instancia ante el $16^{\circ} \mathrm{Juzgado}$ Civil de Santiago bajo el rol C-6698-2012.

${ }^{12}$ Contra la resolución exenta $\mathrm{N}^{\circ} 080$, la señora Cariola interpuso recurso de reposición ante la misma SVS, el cual fue rechazado en todas sus partes mediante resolución exenta $\mathrm{N}^{\circ}$ 148 de 29 de marzo de 2012. Por ello, la señora Cariola dedujo acción de reclamación en juicio sumario contra estas resoluciones que, a la fecha de este comentario, está aún tramitándose en primera instancia ante el $7^{\circ}$ Juzgado Civil de Santiago bajo el rol C-7259-2012.

${ }^{13}$ Contra la resolución exenta $\mathrm{N}^{\circ} 081$, el señor Cortázar interpuso recurso de reposición ante la misma SVS, el cual fue rechazado en todas sus partes mediante resolución exenta $\mathrm{N}^{\circ} 143$ de 28 de marzo de 2012. Por ello, el señor Cortázar dedujo acción de reclamación en juicio sumario contra estas resoluciones que, a la fecha de este comentario, está aún tramitándose en primera instancia ante el $17^{\circ}$ Juzgado Civil de Santiago bajo el rol C-72002012.

${ }^{14}$ Contra la resolución exenta $\mathrm{N}^{\circ} 082$, el señor Gana dedujo acción de reclamación en juicio sumario que, a la fecha de esta comentario, está aún tramitándose en primera instancia ante el $12^{\circ} \mathrm{Juzgado}$ Civil de Santiago bajo el rol C-6445-2012. 
8. Si bien el caso La Polar es emblemático en materia de gobiernos corporativos, nos resulta claro que en estas resoluciones la SVS sigue la doctrina que sentó en el caso FASA ${ }^{15}$, reforzando la obligación que tienen los directores de informarse sobre la marcha de la compañía. Claramente, la SVS recalca el papel activo que debe tener el director al respecto, sin que la falta u ocultación de información o, incluso, la existencia de informes favorables de gatekeepers, lo puedan exonerar de responsabilidad si había indicios suficientes del problema, como así lo considera en este caso la SVS.

Pero, por otra parte, dada la extensión del problema de las renegociaciones, resulta pertinente destacar cómo la SVS pondera el monto de la sanción a aplicar, distinguiendo entre los directores según la duración de sus cargos (desde UF 400 por seis meses en el cargo a UF 2.800 por cuatro a ocho años en el cargo) y si tenían o no la responsabilidad adicional de ser miembros del comité de directores (con un monto adicional de entre UF 300 a UF 700, según la duración en el cargo). Quizá sobre este último punto llame la atención el bajo impacto sancionatorio que genera ser adicionalmente miembro del comité de directores (apenas un $25 \%$ adicional para los miembros de mayor duración), siendo un órgano asesor especializado en temas de auditoría. No parece suficiente que la

\footnotetext{
${ }^{15}$ Véase nuestro comentario a las resoluciones dictadas por la SVS en este caso en el $\mathrm{N}^{\circ} 16$ de esta revista, p. 372 y ss.
}

responsabilidad de este Comité sea sólo un 25\% mayor, bastando compararlo con la exigencia establecida por el artículo 50 bis de la Ley de Sociedades Anónimas, en cuanto a que la remuneración de los directores integrantes del comité:

"no puede ser inferior a la remuneración prevista para los directores titulares, más un tercio de su monto".

\section{BIBLIOGRAFÍA}

Barrientos, Francisca, "Los derechos de los consumidores en el caso La Polar", en Gaceta Jurídica, edición especial Análisis doctrinario y jurisprudencial del caso La Polar, Santiago, Legal Publishing Chile, 2011.

Corral Talciani, Hernán, Caso La Polar: repactaciones irregulares y reparación a los consumidores, en Gaceta Jurídica, edición especial Análisis doctrinario y jurisprudencial del caso La Polar, Santiago, Legal Publishing Chile, 2011.

Gaspar, José Antonio, "Responsabilidad civil de los gatekeepers en el mercado de capitales: análisis de la responsabilidad civil de los auditores externos, clasificadoras de riesgo y analistas financieros en el Caso La Polar", en Fabián Elorriaga de Bonis (coord), Estudios de Derecho Civil VII, Jornadas Nacionales de Derecho Civil, Viña del Mar, 2011, Santiago, Legal Publishing Chile, 2012.

Roa Ramírez, José, "La Polar y modificaciones unilaterales de los contratos", en Gaceta Jurídica, edición especial 
Análisis doctrinario y jurisprudencial del caso La Polar, Santiago, Legal Publishing Chile, 2011. 